\title{
A Five Minute Experience in the Elevated Plus-Maze Alters the State of the Benzodiazepine Receptor in the Dorsal Raphe Nucleus
}

\author{
Luis E. Gonzalez and Sandra E. File \\ Psychopharmacology Research Unit, UMDS Division of Pharmacology, Guy's Hospital, London SE1 9RT, \\ United Kingdom
}

\begin{abstract}
A single $5 \mathrm{~min}$ exposure to the elevated plus-maze test of anxiety renders animals insensitive to the anxiolytic effects of the benzodiazepines in this test. The purpose of the present experiments was to explore whether this phenomenon resulted from a change in the functional state of benzodiazepine receptors in the dorsal raphe nucleus. The benzodiazepine receptor agonist midazolam $(0.5,1$, and $2 \mu \mathrm{g})$ and antagonist flumazenil (100 and $500 \mathrm{ng}$ ) were directly administered to the dorsal raphe nucleus in rats either naive to, or with one previous $5 \mathrm{~min}$ exposure of, the elevated plus-maze. In naive rats, midazolam produced significant anxiolytic effects at all doses, and flumazenil was silent. In plus-maze-experienced rats, midazolam no longer had anxiolytic effects in the plus-maze, but flumazenil did, indicating that the previous experience of the maze had
\end{abstract}

changed the state of the benzodiazepine receptor. This changed receptor function generalized to the social interaction test. Thus, in naive animals tested in high light, midazolam (0.5, 1 , and $2 \mu \mathrm{g}$ ) had significant anxiolytic effects and flumazenil (100 and $500 \mathrm{ng}$ ) was silent, whereas in plus-maze-experienced rats both midazolam $(1 \mu \mathrm{g})$ and flumazenil $(500 \mathrm{ng})$ had significant anxiolytic effects. Extensive analysis of locomotor activity in both tests showed that the changed responsivity to midazolam could not be explained by habituation, because on none of the measures used was there any difference in motor activity scores between plus-maze-naive and experienced rats.

Key words: benzodiazepine receptors; dorsal raphe; midazolam; flumazenil; plus-maze; social interaction
Neuronal inhibition of the dorsal raphe nucleus (DRN) by administration of benzodiazepines (Laurent et al., 1983), 5-HT, or 5-HT $\mathrm{HA}_{1 \mathrm{~A}}$ agonists (Sprouse and Aghajanian, 1987) has evoked anxiolytic effects in various animal tests of anxiety (Thiébot et al., 1980a; Higgins et al., 1988, 1992; Hogg et al., 1994; File and Gonzalez, 1996). Conversely, administration of the benzodiazepine receptor inverse agonist to the DRN has been reported to produce anxiogenic effects in the social interaction test (Jones et al., 1986), the elevated T-maze (Graeff et al., 1996a), and after inescapable shock (Maier et al., 1995). However, no data are available regarding the effects of intra-DRN administration of any benzodiazepine in the elevated plus-maze, a widely used and well validated test of anxiety (Pellow et al., 1985). This would be of particular interest because of evidence that plus-maze experience changes the functioning of the GABA-benzodiazepine system. The chlordiazepoxide-induced reduction in GABA release from cortical slices was abolished by previous plus-maze experience (File, 1993). Also, systemic administration of benzodiazepines does not evoke anxiolytic effects in mice or rats with a 5 min previous experience in the elevated plus-maze (Lister, 1987; File, 1990; Rodgers et al., 1992; File, 1993; Rodgers and Shepherd, 1993; Treit et al., 1993; Rodgers et al., 1996), although the anxiogenic effects of the inverse agonist FG 7142 can be detected

\footnotetext{
Received Oct. 3, 1996; revised Nov. 27, 1996; accepted Dec. 2, 1996.

L.E.G. is supported by a grant from Consejo Nacional de Investigaciones Científicas y Tecnológicas, University of Los Andes, Mérida, Venezuela. We thank P. Mabbutt and M. Guscott for expert technical assistance and Dr. A. Kent, Division of Anatomy, for the use of the cryomat. We especially thank Dr. Nick Andrews for helpful discussions.

Correspondence should be addressed to Sandra E. File, Psychopharmacology Research Unit, UMDS Division of Pharmacology, Guy's Hospital, London SE1 9RT, UK.

Copyright (C) 1997 Society for Neuroscience 0270-6474/97/171505-07\$05.00/0
}

on both trials 1 and 2 (File and Zangrossi, 1993). No conclusive explanation has been found for this phenomenon, but several interesting hypotheses have been proferred, such as modification of the receptor state (File, 1990), locomotor habituation (Dawson et al., 1994), sensitization of fear of the open arms (Rodgers and Shepherd, 1993; Treit et al., 1993), and change in the nature of anxiety evoked on trial 2 (File and Zangrossi, 1993; Rodgers and Shepherd, 1993).

The purpose of the present experiments was to explore how previous plus-maze experience might modify benzodiazepine receptor function in the DRN by testing rats naive to and experienced with the plus-maze after administration of the receptor agonist midazolam and the receptor antagonist flumazenil directly to the DRN. To determine whether any such changes generalized to other tests of anxiety, we also tested naive and plus-mazeexperienced rats in the social interaction test of anxiety. The high light, unfamiliar test condition was selected because it is the most sensitive to the anxiolytic effects of benzodiazepines (File, 1980).

The dose range of midazolam was based on those doses active in previous studies in our laboratory (Gonzalez et al., 1996), and the doses of flumazenil were selected after pilot experiments.

\section{MATERIALS AND METHODS}

\section{Animals}

Male hooded Lister rats weighing 200-300 gm (Harlan) were housed singly after surgery and allowed to recover for $7 \mathrm{~d}$ before behavioral testing. Food and water were freely available, and the room in which they were housed was lit with dim light and maintained at $22^{\circ} \mathrm{C}$. Lights were on from 7 A.M. to 7 P.M. After surgery, animals were singly housed and allowed to recover for $7 \mathrm{~d}$ before behavioral testing. To accustom the animals to handling and to keep the cannulae patent, each day the rats were gently wrapped in a cloth and the stylets were replaced. All of the experimental groups had 12-13 animals per group before surgery. The final group sizes reflect the loss of animals postoperatively because of 
displacement of the cannula mounting, the blockade of the cannula, and the results of the histological analysis.

\section{Apparatus}

The plus-maze was made of wood and consisted of two opposite open arms $50 \times 10 \mathrm{~cm}$, and two opposite arms enclosed by $40 \mathrm{~cm}$ high walls. The arms were connected by a central $10 \times 10 \mathrm{~cm}$ square, and thus the maze formed a "plus" shape. The maze was elevated $50 \mathrm{~cm}$ from the floor and lit by dim light. A closed-circuit TV camera was mounted vertically over the maze, and the behavior was scored from a monitor in an adjacent room. All scores were entered directly into an IBM computer. Changes in the percentage of time spent on the open arms indicate changes in anxiety (Pellow et al., 1985), and number of closed arm entries is the best measure of locomotor activity (File, 1992). Because locomotor activity has been claimed to be a factor involved in the habituation to the elevated plus-maze (Dawson et al., 1994), additional measures (distance traveled and velocity) were also assessed retrospectively from the video film (experiment 1). Therefore, the plus-maze was divided into equal areas $(10 \times 15.7 \mathrm{~cm})$ by placing a grid over the video screen. The number of line crossings was scored by an observer blind to the drug treatment, which allowed an estimation of the distance covered by the animals.

The social interaction test arena was a wooden box $60 \times 60 \mathrm{~cm}$, with 35 $\mathrm{cm}$ high walls, and the test room was lit by high light (350 lux). A camera was mounted vertically above the arena, and the rats were observed on a monitor in an adjacent room. Test sessions were also video recorded for subsequent analysis. Infrared photocells were mounted in the walls 4.5 and $12 \mathrm{~cm}$ from the floor, and the interruption of these beams provided automated measures of locomotor activity and rearing, respectively.

\section{Drugs}

Midazolam maleate and flumazenil were both kindly donated by Roche Products and prepared in $0.9 \%$ sodium chloride solution.

\section{Surgery}

Rats were anesthetized by inhalation of $3 \%$ halothane (May and Baker) in oxygen and positioned in a stereotaxic frame (Kopf Instruments). The skull was exposed, and the incisor bar was adjusted for each rat such that bregma and lambda were at the same height. Three indentations were made in the skull to accommodate screws that, together with the application of dental cement, held the cannulae in place. For cannulation of the DRN, 12-mm-long steel guide cannulae (23 gauge, Cooper's Needle Works, Birmingham, England) were positioned at $7.2 \mathrm{~mm}$ posterior to bregma, $+2.2 \mathrm{~mm}$ lateral, and $-4.7 \mathrm{~mm}$ vertical at an angle of $19^{\circ}$ (this coordinate was taken from the dura), thus placing it $2 \mathrm{~mm}$ above the target area. Cannulae were kept patent using 12-mm-long stainless steel stylets (30 gauge, Cooper's Needle Works).

\section{Behavioral testing}

\section{Elevated plus-maze}

On the test day, rats were gently wrapped in a cloth and injected using needles constructed from 30 gauge steel tubing that extended $2 \mathrm{~mm}$ below the tip of the in-dwelling cannulae. Injections $(0.5 \mu \mathrm{l})$ were made over a period of $30 \mathrm{sec}$ using a flow rate of $1 \mu \mathrm{l} / \mathrm{min}$ delivered by a microdialysis pump; the needles were left in position an additional $30 \mathrm{sec}$ to allow drug diffusion. Three minutes later, each rat was placed in the central square of the plus-maze facing a closed arm, and its behavior was observed for 5 min by an observer blind to the drug treatment. The number of entries onto open and closed arms and the times spent in open and closed arms and in the central square were scored. Testing took place between 8 A.M. and 1 P.M. in an order randomized for drug treatment in a room lit by dim light $(<50$ lux $)$ from a light source directly above the plus-maze. Different animals were used for the different drug treatments. The arena was wiped thoroughly with damp tissue after each trial.

\section{The social interaction test}

Rats were allocated to unoperated partners on the basis of body weight, such that members of a pair did not differ by more than $10 \mathrm{gm}$. On the test day, the operated rats were injected following the same procedure described for the elevated plus-maze test. Three minutes later, the pair was placed in the social interaction arena. The behavior was observed for 7.5 min by an observer blind to the drug treatment who scored the time spent in active social interaction (sniffing, following, allogrooming, wrestling, biting, and kicking the partner) by the operated rat, which was entered into a computer. Testing was performed between 8 A.M. and 12 P.M. in an order randomized for drug treatment, and the arena was wiped thoroughly after each trial. Testing took place over $2 \mathrm{~d}$, and vehicle control animals were tested on each day; different sets of rats were used in each experiment.

\section{Allocation to drug groups}

For all of the experiments, animals were allocated either to a plus-maze exposure or nonexposure condition. Therefore, on day 7 after surgery, rats in the exposure condition were placed individually onto the central platform of the plus-maze, removed 5 min later, and returned to the home cage for an additional $4 \mathrm{~d}$. Exposed and nonexposed rats were then randomly allocated among the drug groups. The numbers in parentheses indicate those with verified cannulae placements.

\section{Experiment 1}

\section{Effects of midazolam in the plus-maze in naive and experienced rats}

Plus-maze-naive rats. Vehicle $(n=13)$; midazolam $0.5 \mu \mathrm{g}(n=10), 1 \mu \mathrm{g}$ $(n=10)$, or $2 \mu \mathrm{g}(n=11)$.

Plus-maze-experienced rats. Vehicle $(n=13)$; midazolam $0.5 \mu \mathrm{g}(n=$ $10) ; 1 \mu \mathrm{g}(n=11)$, and $2 \mu \mathrm{g}(n=10)$.

\section{Experiment 2}

Effects of midazolam in the social interaction test in naive and plus-maze-experienced rats

Plus-maze-naive. Vehicle $(n=8)$; midazolam $0.5 \mu \mathrm{g}(n=9), 1 \mu \mathrm{g}(n=$ $7)$, and $2 \mu \mathrm{g}(n=7)$.

Plus-maze-experienced. Vehicle $(n=10)$; midazolam $0.5 \mu \mathrm{g}(n=10), 1$ $\mu \mathrm{g}(n=10)$, and $2 \mu \mathrm{g}(n=10)$.

\section{Experiment 3}

\section{Effects of flumazenil in the plus-maze in naive and} experienced rats

Plus-maze-naive. Vehicle $(n=9)$; midazolam $1 \mu \mathrm{g}(n=5)$; flumazenil $100 \mathrm{ng}(n=8)$ and $500 \mathrm{ng}(n=7)$; flumazenil $500 \mathrm{ng}+$ midazolam 1 $\mu \mathrm{g}(n=6)$.

Plus-maze-experienced. Vehicle $(n=9)$; midazolam $1 \mu \mathrm{g}(n=8)$; flumazenil $500 \mathrm{ng}(n=7)$; midazolam $1 \mu \mathrm{g}+$ flumazenil $500 \mathrm{ng}(n=7)$.

\section{Experiment 4}

Effects of flumazenil in the social interaction test in naive and plus-maze-experienced rats

Plus-maze-naive. Vehicle $(n=11)$; midazolam $1 \mu \mathrm{g}(n=7)$; flumazenil $100 \mathrm{ng}(n=7)$ and $500 \mathrm{ng}(n=8)$; flumazenil $500 \mathrm{ng}+$ midazolam $1 \mu \mathrm{g}$ $(n=7)$.

Plus-maze-experienced. Vehicle $(n=11)$; midazolam $1 \mu \mathrm{g}(n=6)$; flumazenil $500 \mathrm{ng}(n=11)$; midazolam $1 \mu \mathrm{g}$ + flumazenil $500 \mathrm{ng}(n=7)$.

\section{Histology}

At the end of behavioral testing, all operated animals were sacrificed, the brains were removed, and the injection site was verified histologically (according to the atlas of Paxinos and Watson, 1986) by a person blind to drug treatment. Frozen brains were sectioned on a British cryomat at 20 $\mu \mathrm{m}$. Sections were obtained parallel to the stereotaxic planes by adjusting the angle of cutting.

Figure 1, depicting coronal slices through the DRN, shows the target sites as shaded, and the positions of the tips of the injection needles for the animals are excluded (not in the target area) from statistical analysis.

\section{Statistics}

All of the social interaction and plus-maze scores were subjected to ANOVA with Duncan's post hoc tests for differences between individual groups. It is the significance of these that are shown in the figures and tables.

\section{RESULTS}

\section{Experiment 1}

Effects of midazolam in the plus-maze of naive and experienced rats

In plus-maze-naive rats (trial 1 ), microinjections of midazolam $(0.5,1$, and $2 \mu \mathrm{g})$ into the DRN increased the percentage of time spent on the open arms $\left[F_{(3,40)}=6.9, p<0.001\right]$, and this 


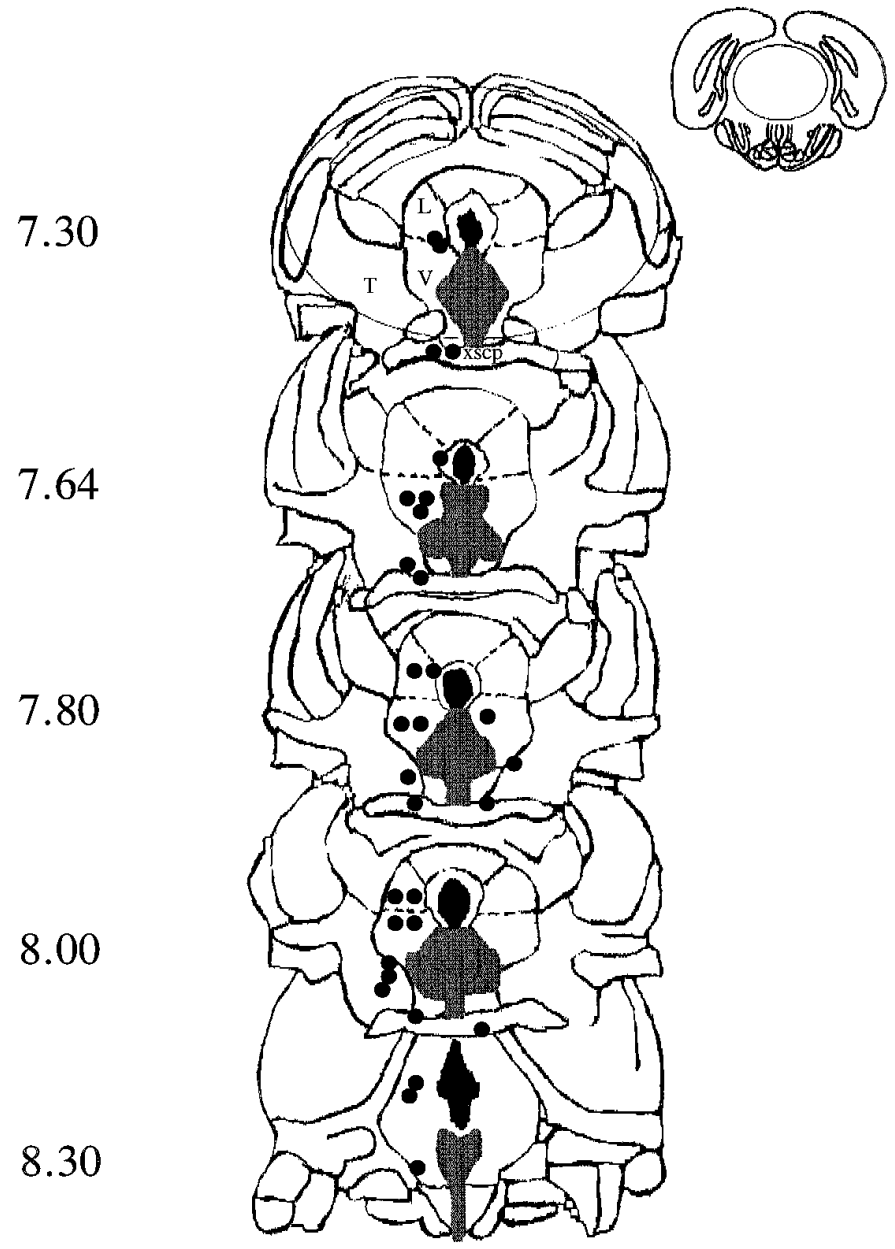

Figure 1. Diagrammatic representation of coronal sections from 7.3 to $8.3 \mathrm{~mm}$ posterior to bregma (Paxinos and Watson, 1986) showing the target area (shaded) of the dorsal raphe nucleus. Placements falling outside the target areas are shown by filled circles marking the site of the tip of the injection needle. $L$, Central gray lateral dorsal; $V$, central gray lateral ventral; $T$, tegmental area; xscp, decussation superior cerebellar peduncle.

anxiolytic effect was significant for all doses (Fig. 2). No effects were detected on the number of closed arm entries, total arm entries, the distance covered by the animals, or the speed of locomotion (Table 1). This pattern of results shows that midazolam administered to the DRN has a clear anxiolytic effect on trial 1 in the plus-maze. In contrast, in plus-maze-experienced rats (trial 2), no anxiolytic effects were observed [for percentage of time spent on open arms, $F_{(3,43)}=0.02$ ] (Fig. 2), and there were no changes in the measures of locomotor activity (Table 1$)$.

\section{Experiment 2}

Effects of midazolam in the social interaction test in naive and plus-maze-experienced rats

Microinjections of midazolam $(0.5,1$, and $2 \mu \mathrm{g})$ into the DRN increased the time spent in social interaction of plus-maze-naive and exposed rats $\left[F_{(3,27)}=5.2, p<0.01\right.$ and $F_{(3,36)}=4.3, p<$ 0.01 , respectively], and these effects were significant for the doses of 1 and $2 \mu \mathrm{g}$ (Fig. 3). No significant changes in locomotor activity or rears were observed (see Table 1), thus indicating a specific anxiolytic effect.

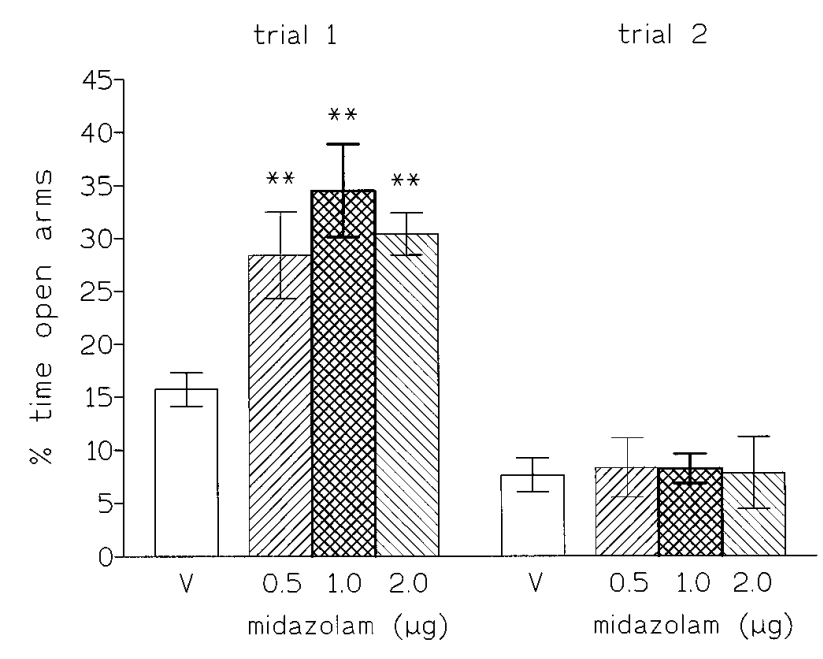

Figure 2. Percentage of time spent (mean \pm SEM) on open arms by rats injected into the dorsal raphe nucleus with saline $(V)$ or midazolam $(0.5$, 1 , and $2 \mu \mathrm{g}$ ). Testing was for $5 \mathrm{~min} .{ }^{* *} p<0.01$ compared with vehicle control.

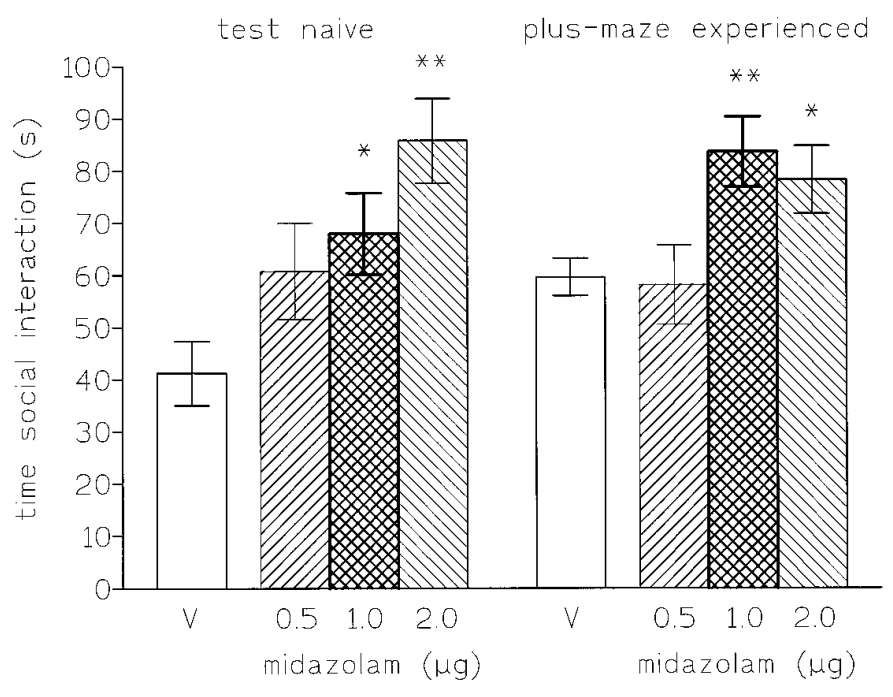

Figure 3. Time spent (mean \pm SEM) in social interaction $(s)$ by rats injected into the dorsal raphe nucleus in high light, unfamiliar conditions with saline $(V)$ or midazolam $(0.5,1$, and $2 \mu \mathrm{g})$. The scores are expressed as the cumulative time (sec) during 7.5 min of testing. ${ }^{*} p<0.05$ compared with vehicle control; ${ }^{* *} p<0.01$ compared with vehicle control.

\section{Experiment 3}

Effects of midazolam and flumazenil in the plus-maze in naive and experienced rats

In plus-maze-naive rats (trial 1), microinjections of midazolam $(1 \mu \mathrm{g})$ into the DRN significantly increased the percentage of time spent on the open arms $(p<0.05)$, but flumazenil (100 and $500 \mathrm{ng}$ ) was without effect; however, on trial 2, whereas midazolam was without effect, flumazenil now significantly increased the percentage of time spent on the open arms $(p<$ 0.05 ; see Fig. 4). On both trials 1 and 2, the combination of midazolam + flumazenil significantly increased the percentage of time spent on the open arms $(p<0.01$ and $p<0.05$, respectively). There were no significant changes in the number of closed arm entries or the total number of arm entries for any of the drug treatments (Table 2). 
Table 1. Mean ( \pm SEM) number of closed and total arm entries, total distance traveled $(\mathrm{m})$, and velocity $(\mathrm{cm} / \mathrm{sec})$ by rats in the plus-maze $($ trials 1 and 2)

\begin{tabular}{|c|c|c|c|c|c|}
\hline \multirow[b]{2}{*}{ Locomotor measures } & \multirow[b]{2}{*}{ Vehicle (saline) } & \multicolumn{3}{|c|}{ Midazolam $(\mu \mathrm{g})$} & \multirow[b]{2}{*}{$F$ ratio } \\
\hline & & 0.5 & 1 & 2 & \\
\hline \multicolumn{6}{|l|}{ No. of closed entries } \\
\hline trial 1 & $8.5 \pm 0.1$ & $7.5 \pm 1.0$ & $7.3 \pm 0.4$ & $7.3 \pm 0.5$ & 0.9 \\
\hline trial 2 & $11.4 \pm 1.0$ & $10.1 \pm 1.5$ & $11.8 \pm 1.0$ & $8.9 \pm 0.7$ & 1.6 \\
\hline \multicolumn{6}{|l|}{ Total arm entries } \\
\hline trial 1 & $12.2 \pm 0.7$ & $12.6 \pm 0.9$ & $12.9 \pm 0.8$ & $12.0 \pm 0.8$ & 0.1 \\
\hline trial 2 & $13.7 \pm 1.2$ & $11.8 \pm 1.6$ & $14.6 \pm 0.9$ & $11.2 \pm 1.4$ & 1.5 \\
\hline \multicolumn{6}{|l|}{ Distance (m) } \\
\hline trial 1 & $12.4 \pm 0.4$ & $10.9 \pm 0.5$ & $12.4 \pm 0.6$ & $13.2 \pm 1.4$ & 0.8 \\
\hline trial 2 & $13.2 \pm 1.0$ & $12.0 \pm 9.3$ & $13.4 \pm 0.7$ & $10.4 \pm 1.4$ & 1.6 \\
\hline \multicolumn{6}{|l|}{ Velocity $(\mathrm{cm} / \mathrm{sec})$} \\
\hline trial 1 & $4.2 \pm 0.1$ & $3.6 \pm 0.2$ & $4.1 \pm 0.2$ & $4.4 \pm 0.5$ & 1.1 \\
\hline trial 2 & $4.4 \pm 0.3$ & $4.0 \pm 0.4$ & $4.5 \pm 0.2$ & $3.4 \pm 0.5$ & 1.6 \\
\hline \multicolumn{6}{|c|}{ Locomotor (beam breaks) } \\
\hline naive & $520.3 \pm 35.3$ & $550.5 \pm 46.5$ & $530.1 \pm 34.1$ & $528.0 \pm 33.8$ & 0.9 \\
\hline experience & $594.0 \pm 28.7$ & $535.9 \pm 27.1$ & $584.9 \pm 34.1$ & $511.7 \pm 29.3$ & 1.7 \\
\hline \multicolumn{6}{|l|}{ Rears (beam breaks) } \\
\hline naive & $37.5 \pm 1.6$ & $39.0 \pm 1.3$ & $37.1 \pm 4.6$ & $35.9 \pm 2.4$ & 0.9 \\
\hline experience & $31.9 \pm 2.0$ & $38.4 \pm 5.2$ & $32.1 \pm 2.1$ & $38.1 \pm 5.4$ & 1.2 \\
\hline
\end{tabular}

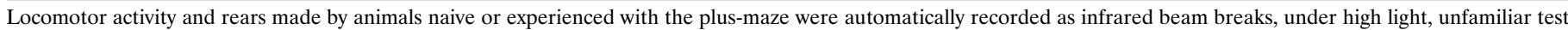
conditions in the social interaction test after intra-DRN injections. The $F$ ratios refer to the midazolam factor and in all cases were nonsignificant.

Figure 4. Percentage of time spent (mean \pm SEM) on open arms by rats injected into the dorsal raphe nucleus with saline (v), flumazenil (100-500 ng), midazolam (1 $\mu \mathrm{g})$, or flumazenil $(500 \mathrm{ng})+$ midazolam $(1 \mu \mathrm{g})$. Testing was for 5 min for trials 1 and $2 . * p<0.05 ; * * p<0.01$ compared with vehicle control. ${ }^{+} p<0.05$ compared with midazolam + flumazenil group.

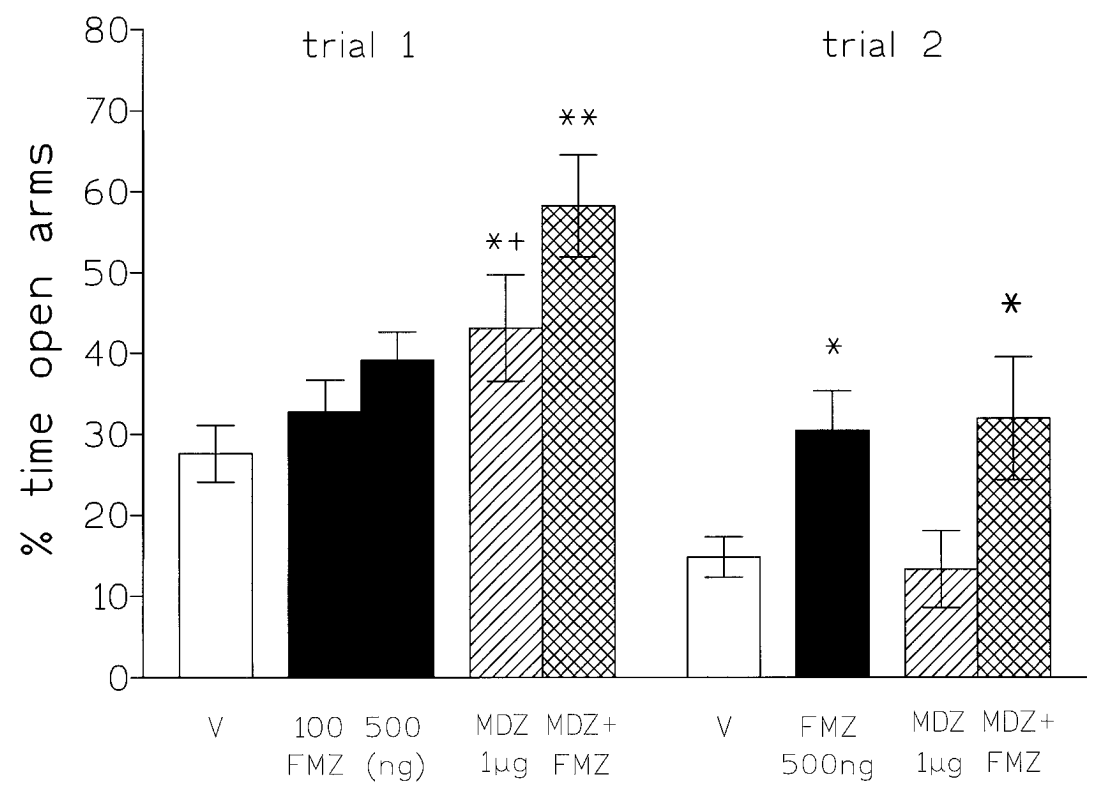

remained anxiolytic. No significant changes in locomotor activity or rears were observed (Table 2).

\section{Injections falling outside the DRN}

Injections sites falling outside the DRN are depicted in Figure 1. All animals having these injections were excluded from the statistical analyses presented above. However, the behavioral scores from these rats provide useful information on the anatomical specificity of the injections and are presented below for sites where we had scores for at least three rats. There was clear evidence that when the injection site fell outside the periaqueductal gray, there were no drug effects. Thus, when midazolam ( 1 and 
Table 2. Mean ( \pm SEM) number of closed arm entries made by rats in the plus-maze (trials 1 and 2$)$

\begin{tabular}{|c|c|c|c|}
\hline Treatment & $\begin{array}{l}\text { Number of closed } \\
\text { arm entries }\end{array}$ & $\begin{array}{l}\text { Locomotor } \\
\text { activity } \\
\text { (beam breaks) }\end{array}$ & $\begin{array}{l}\text { Rears } \\
\text { (beam breaks) }\end{array}$ \\
\hline \multicolumn{4}{|l|}{ Maze naive } \\
\hline Vehicle (saline) & $9.9 \pm 1.2$ & $686.9 \pm 29.0$ & $32.0 \pm 1.9$ \\
\hline MDZ (1 $\mu \mathrm{g})$ & $10.6 \pm 1.2$ & $727.6 \pm 22.1$ & $26.4 \pm 1.7$ \\
\hline FMZ (100 ng) & $9.6 \pm 1.1$ & $684.4 \pm 28.0$ & $30.6 \pm 1.8$ \\
\hline FMZ (500 ng) & $10.0 \pm 1.1$ & $770.5 \pm 19.5$ & $29.1 \pm 1.1$ \\
\hline $\mathrm{MDZ}+\mathrm{FMZ}$ & $9.0 \pm 1.1$ & $660.7 \pm 42.9$ & $34.1 \pm 2.0$ \\
\hline$F_{(4,34)}$ & 0.2 & 2.0 & 1.0 \\
\hline \multicolumn{4}{|l|}{ Maze experienced } \\
\hline Vehicle (saline) & $13.1 \pm 0.9$ & $588.6 \pm 40.7$ & $31.1 \pm 2.0$ \\
\hline $\operatorname{MDZ}(1 \mu \mathrm{g})$ & $11.9 \pm 0.9$ & $623.0 \pm 36.7$ & $24.3 \pm 2.1$ \\
\hline FMZ (500 ng) & $12.3 \pm 1.0$ & $661.5 \pm 33.7$ & $28.5 \pm 1.8$ \\
\hline $\mathrm{MDZ}+\mathrm{FMZ}$ & $11.9 \pm 1.3$ & $622.6 \pm 83.7$ & $27.6 \pm 3.4$ \\
\hline$F_{(3,31)}$ & 0.3 & 0.2 & 0.7 \\
\hline
\end{tabular}

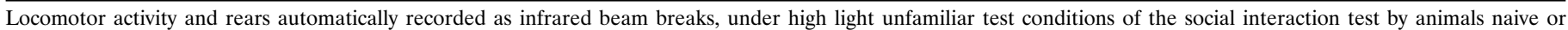
experienced with the elevated plus-maze. $F$ ratios refer to the drug treatment factor and in all cases were nonsignificant. MDZ, Midazolam; FMZ, flumazenil.

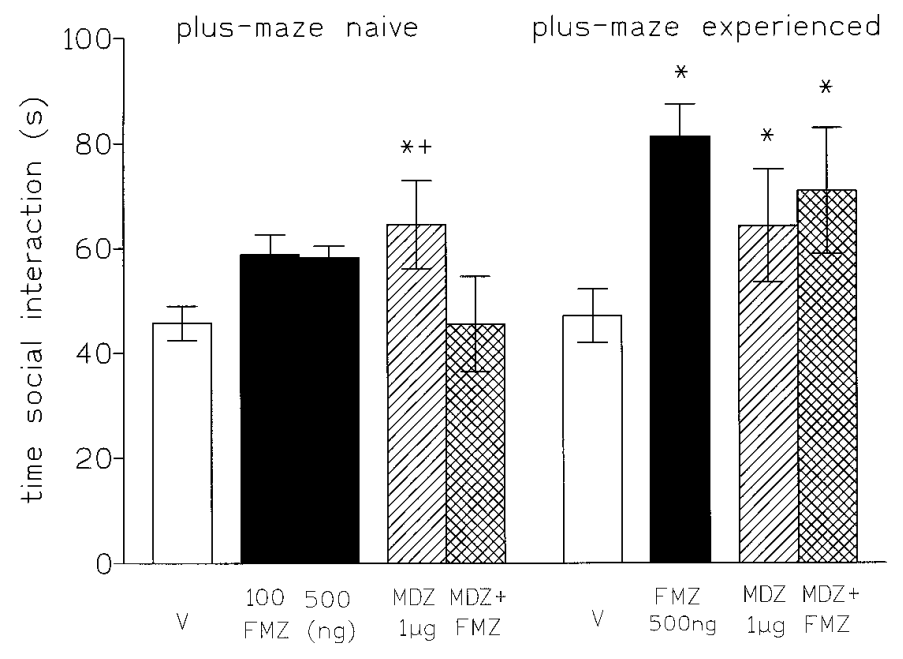

Figure 5. Time spent (mean \pm SEM) in social interaction (sec) by rats naive to or experienced with the plus-maze by rats injected into the dorsal raphe nucleus in high light, unfamiliar test conditions with saline $(V)$, flumazenil (100-500 ng), midazolam $(1 \mu \mathrm{g})$, or flumazenil $(500 \mathrm{ng})+$ midazolam $(1 \mu \mathrm{g})$. The scores are expressed as the cumulative time (in seconds) during $7.5 \mathrm{~min}$ of testing. ${ }^{*} p<0.05$ compared with vehicle control.

$2 \mu \mathrm{g})$ was injected into the decussation superior of cerebellum (xscp) or the tegmental area (T), the percentage of time spent on the open arms on trial 1 of the plus-maze did not differ from that of the vehicle-treated animals [mean \pm SEM: $x \operatorname{xsp}(n=4): 14.7 \pm$ 2.2; T $(n=3): 13.2 \pm 3.1$; vehicle: $15.7 \pm 1.6]$ or the time spent (s) in social interaction $[\mathrm{xscp}+\mathrm{T}(n=3)$ : $47.5 \pm 1.6$; vehicle: $45.7 \pm 3.3]$.

However, injections falling outside the DRN, but still within the periaqueductal gray, did have effects, although in an opposite direction. Thus, on trial 2 in the plus-maze, when flumazenil (500 $\mathrm{ng}$ ) was injected into the central gray lateral dorsal and ventral (L and $\mathrm{V}$ ), the scores were lower than those from vehicle-treated rats $[\mathrm{L}+\mathrm{V}(n=4): 5.4 \pm 1.7$; vehicle: $14.8 \pm 2.5]$ in sharp contrast to the high scores evoked by flumazenil injections in the target area of the DRN $(30.5 \pm 4.9)$. When flumazenil was injected into the aqueduct itself, the scores were also lower that those from control [aqueduct $(n=4)$ : $14.6 \pm 0.7$; vehicle: $27.6 \pm 3.5$ ].

\section{DISCUSSION}

These experiments have clearly shown that administration of midazolam to the DRN has significant anxiolytic effects in the elevated plus-maze, when naive rats are tested. These effects are no longer found when testing animals with a previous $5 \mathrm{~min}$ exposure to the plus-maze. It is striking that an experience as brief as 5 min can have such marked effects, and recent studies (Rodgers et al., 1996) have shown that even the first $3 \mathrm{~min}$ in the plus-maze are crucial. The results of these experiments allow us to address several of the hypotheses advanced to explain the reduced sensitivity to benzodiazepines on trial 2 in the elevated plus-maze. First, using several different measures of locomotor activity, we found no evidence for any decrease in these measures from trial 1 to trial 2, nor did the drug treatments change these measures. Therefore, there is little to support the suggestion (Dawson et al., 1994) that locomotor habituation is the explanation for reduced anxiolytic effects of benzodiazepines on trial 2 .

The possibility that trial 2 in the plus-maze evokes greater fear/anxiety (Rodgers and Shepherd, 1993; Treit et al., 1993) is supported by the finding of a lower percentage of time spent on the open arms on trial 2 than trial 1; one mechanism for mediating such a change in scores would be the shift to an inverse agonist state of the benzodiazepine receptor, as indicated by the anxiolytic effects of flumazenil in plus-maze-experienced rats. The benzodiazepine receptors in the DRN have been shown to be sensitive to the anxiogenic or fear-enhancing properties of inverse agonists (Jones et al., 1986; Guidotti, 1991; Maier et al., 1995). The presence of endogenous ligands with inverse agonist properties, or the shift in the receptor to the inverse agonist state, would explain the lack of anxiolytic action of midazolam, because its agonist effects would be counteracted by the inverse agonist effects. Even on trial 1 there is some evidence for the presence of an inverse agonist ligand that approached significance [because flumazenil (500 ng) had an anxiolytic effect]. Antagonism of such a ligand might explain the additive effects of midazolam and flumazenil, and would be particularly likely if it were acting at a diazepam-insensitive site, at which flumazenil, but not midazolam, is active (Turner et al., 1991). 
The results from testing rats in the social interaction test suggest that the change in benzodiazepine receptor state is not just triggered by reexposure to the plus-maze. Flumazenil had significant anxiolytic effects in the social interaction test in rats with previous plus-maze experience, whereas it was silent in naive rats. This suggests that the changed state generalizes, at least to some extent, to other tests of anxiety, as has been found previously for mice (Rodgers and Shepherd, 1993). However, the change was not as marked when the rats were tested in the social interaction test, because midazolam was still able to produce significant anxiolytic effects, suggesting that the inverse agonist shift was less than that seen when rats were retested in the plus-maze.

There is considerable evidence that, rather than just evoking more fear by trial 2, a different form of fear is evoked by the test situation. Principal component analyses have shown that the measures of anxiety on trials 1 and 2 load on two independent factors, thus indicating that different underlying states are being measured on the two trials (File et al., 1993; Rodgers and Johnson, 1995; Fernandes and File, 1996). The DRN seems particularly sensitive to different aspects of tests of anxiety. Thus, Graeff et al. (1996b) have shown that administration of the $5-\mathrm{HT}_{1 \mathrm{~A}}$ receptor agonist 8-OH-DPAT to the DRN impairs inhibitory avoidance of, but does not change escape from, the open, elevated arms of a T-maze. File and Gonzalez (1996) also found that the DRN was differentially sensitive to 8-OH-DPAT in plus-maze-naive and experienced rats. Thus, 8-OH-DPAT was without effect in naive rats, but it had anxiolytic effects on trial 2 . This had suggested that the level of neuronal activity of the serotonergic neurons in the DRN was much higher on trial 2 than on trial 1, and hence the inhibitory effects of stimulating the $5-\mathrm{HT}_{1 \mathrm{~A}}$ autoreceptors were more marked on trial 2.

If this conclusion is correct, it suggests that increased neuronal activity of the serotonergic neurons in the DRN does not correlate with the efficacy of benzodiazepine receptor agonists, because their anxiolytic effects are abolished with the experience in the plus-maze. In fact, the evidence for a direct inhibitory effect of benzodiazepines on neuronal activity in the DRN is rather weak and controversial. Gallager (1978) reported that systemic or local administration of benzodiazepines did not alter the firing rate of DRN neurons, although it did potentiate the inhibitory effect of GABA. Levine and Jacobs (1992) found that the GABA antagonist bicuculline reversed the suppression of DRN serotonergic activity during slow-wave sleep but not in awake cats, suggesting that there was little GABA inhibitory tone in the latter state. Trulson et al. (1982) failed to detect changes in firing rate of serotonergic raphe neurons after systemic administration of benzodiazepines at doses commonly used to produce anxiolytic effects in freely moving cats $(0.5-1 \mathrm{mg} / \mathrm{kg})$, but they found decreases in the raphe unit activity at high doses that also induced ataxia. The observation that the neuronal activity in the DRN is relatively insensitive to the action of benzodiazepine receptor agonists, as reported in electrophysiological studies (Gallager, 1978), contrasts with their exquisite sensitivity for inhibitory effects of $5-\mathrm{HT}_{1 \mathrm{~A}}$ receptor agonists (Jolas et al., 1995) and reuptake inhibitors (Hajos et al., 1995).

Thiébot (1980b) has also advised caution in concluding that the anxiolytic effect of benzodiazepines depends exclusively on a selective effect on serotonergic neurotransmission. She failed to detect anxiolytic effects after application of muscimol to the DRN or potentiation of the anxiolytic effects of diazepam when muscimol was administered into the DRN. Furthermore, the anxiolytic effect of diazepam remained unchanged after lesions of the sero- tonergic neurons in the DRN (Thiébot et al., 1984). Therefore, it is possible that the anxiolytic effects of benzodiazepines depend on inhibition of nonserotonergic neurons in the DRN. There is electrophysiological and histochemical evidence that the DRN receives dopaminergic (Lee et al., 1987), noradrenergic (Baraban and Aghajanian, 1981), glutamatergic (Levine and Jacobs, 1992), and enkephalinergic projections (Wang and Nakai, 1993), and apparently a high proportion of cells in the DRN are not serotonergic (Aghajanian et al., 1978).

With central injections, the possibility of spread to other brain areas must always be considered. This is particularly important in the case of the DRN because of its close proximity to the aqueduct. However, the anatomical specificity of our results is suggested by the fact that injections of midazolam that fell outside the periaqueductal gray were without effects. The animals injected with flumazenil just outside the DRN had anxiogenic effects on trial 2, contrasting with the anxiolytic effects of animals injected in the DRN. These injections of flumazenil were in the periaqueductal gray, an area that has been proposed to have a major role in regulating anxiety and a direct functional connection with the DRN (Graeff, 1991).

In summary, the present data lend support to the following conclusions. (1) Experience in the plus-maze releases an endogenous inverse agonist that binds to and desensitizes the benzodiazepine receptors. (2) The presence of this changed state of benzodiazepine receptors is manifest during retesting, especially during a second 5 min exposure to the plus-maze. (3) The DRN is at least one anatomical locus for this change in receptor state. In combination with the results of our previous study using injections of 8-OH-DPAT into the DRN (File and Gonzalez, 1996), it seems that the anxiolytic effects of benzodiazepine agonists in the DRN are attributable to inhibition of nonserotonergic neurons.

\section{REFERENCES}

Aghajanian GK, Wang RY, Baraban J (1978) Serotonergic and nonserotonergic neurons of the dorsal raphe: reciprocal changes in firing induced by peripheral nerve stimulation. Brain Res 153:169-175.

Baraban JM, Aghajanian GK (1981) Noradrenergic innervation of serotonergic neurons in the dorsal raphe: demonstration by electron microscopic autoradiography. Brain Res 204:1-11.

Dawson GR, Crawford SP, Stanhope KJ, Iversen SD, Tricklebank MD (1994) One-trial tolerance to the effects of chlordiazepoxide on the elevated plus-maze may be due to locomotor habituation, not repeated drug exposure. Psychopharmacology 113:570-572.

Fernandes C, File SE (1996) The influence of open arm ledges and maze experience in the elevated plus-maze. Pharmacol Biochem Behav 54:31-40.

File SE (1980) The use of social interaction as a method for detecting anxiolytic activity of chlordiazepoxide-like drugs. J Neurosci Methods 2:219-238.

File SE (1990) One-trial tolerance to the anxiolytic effects of chlordiazepoxide in the plus-maze. Psychopharmacology 100:281-282.

File SE (1992) Behavioural detection of anxiolytic action. In: Experimental approaches to anxiety and depression (Elliott JM, Heal DJ, Marsden CA, eds), pp 25-44. Chichester, UK: Wiley.

File SE (1993) The interplay of learning and anxiety in the elevated plus-maze. Behav Brain Res 58:199-202.

File SE, Gonzalez LE (1996) Anxiolytic effects in the plus-maze of $5-\mathrm{HT}_{1 \mathrm{~A}}$-receptor ligands in dorsal raphe and ventral hippocampus. Pharmacol Biochem Behav 54:123-128.

File SE, Zangrossi H (1993) "One-trial tolerance" to the anxiolytic actions of benzodiazepines in the elevated plus-maze, or the development of a phobic state? Psychopharmacology 110:240-244.

File SE, Zangrossi H, Viana M, Graeff FG (1993) Trial 2 in the elevated plus-maze: a different form of fear? Psychopharmacology 111:491-494.

Gallager DW (1978) Benzodiazepines: potentiation of a GABA inhibitory response in the dorsal raphe nucleus. Eur J Pharmacol 49:133-143.

Gonzalez LE, Andrews N, File SE (1996) 5- $\mathrm{HT}_{1 \mathrm{~A}}$ and benzodiazepine 
receptors in the basolateral amygdala modulate anxiety in the social interaction test, but not in the elevated plus-maze. Brain Res 732:145-153.

Graeff FG (1991) Neurotransmitters in the dorsal periaqueductal grey and animal models of panic anxiety. In: New concepts in anxiety (Briley M, File SE, eds), pp 288-307. Basingstoke Hampshire, UK: Macmillan.

Graeff FG, Viana MB, Mora PO (1996a) Opposed regulation by dorsal raphe nucleus 5-HT pathways of two types of fear in the elevated T-maze. Pharmacol Biochem Behav 53:171-177.

Graeff FG, Guimarâes FS, De Andrade TGS, Deakin JFW (1996b) Role of 5-HT in stress, anxiety and depression. Pharmacol Biochem Behav 54:129-141.

Guidotti A (1991) Role of DBI in brain and its posttranslational processing products in normal and abnormal behavior. Neuropharmacology 30:1425-1433.

Hajos M, Gartside SE, Sharp T (1995) Inhibition of median and dorsal raphe neurones following administration of the selective serotonin reuptake inhibitor paroxetine. Naunyn Schmiedebergs Arch Pharmacol 35:624-629.

Higgins GA, Bradbury AJ, Jones BJ, Oakley NR (1988) Behavioural and biochemical consequences following activation of $5-\mathrm{HT}_{1}$-like and GABA receptors in the dorsal raphe nucleus of the rat. Neuropharmacology 27:993-1001.

Higgins GA, Jones BJ, Oakley NR (1992) Effects of 5-HT 1 A receptor agonists in two models of anxiety after dorsal raphe injection. Psychopharmacology 106:261-267.

Hogg S, Andrews N, File SE (1994) Contrasting behavioural effects of 8-OH-DPAT in the dorsal raphe nucleus and ventral hippocampus. Neuropharmacology 33:343-348.

Jolas T, Schreiber R, Laporte AM, Chastane M, DeVry J, Glaser T, Andrien J, Hamon M (1995) Are post-synaptic 5-HT $\mathrm{HA}_{1 \mathrm{~A}}$ receptors involved in the anxiolytic effects of $5-\mathrm{HT}_{1 \mathrm{~A}}$ receptor agonists and in their inhibitory effects on the firing of serotonergic neurons in the rat? J Pharmacol Exp Ther 272: 920-929.

Jones BJ, Paterson IA, Roberts MHT (1986) Microinjections of methyl$\beta$-carboline-3-carboxilate into the dorsal raphe nucleus: behavioural consequences. Pharmacol Biochem Behav 24:1487-1489.

Laurent JP, Mangold M, Humbel V, Haefely W (1983) Reduction by two benzodiazepines and pentobarbitone of the multiunit activity of substantia nigra, hippocampus, nucleus locus coeruleus and nucleus raphe dorsalis of encephale isole rats. Neuropharmacology 22:501-511.

Lee EH, Wang FB, Tang YP, Geyer MA (1987) GABAergic interneurones in the dorsal raphe mediate the effects of apomorphine on serotonergic system. Brain Res Bull 18:345-353.

Levine ES, Jacobs BL (1992) Neurochemical afferents controlling the activity of serotonergic neurons in the dorsal raphe nucleus: microiontophoretic studies in the awake cat. J Neurosci 12:4037-4044.

Lister R (1987) The use of a plus-maze to measure anxiety in the mouse. Psychopharmacology 92:180-185.
Maier SF, Busch CR, Maswood S, Grahn RE, Watkins LR (1995) The dorsal raphe nucleus is a site of action mediating the behavioural effects of the benzodiazepine receptor inverse agonist DMCM. Behav Neurosci 109:759-766.

Paxinos G, Watson $\mathrm{CH}$ (1986) The rat brain in stereotaxic coordinates. London: Academic.

Pellow S, Chopin PH, File SE, Briley M (1985) Validation of open:closed arm entries in an elevated plus-maze as a measure of anxiety in the rat. J Neurosci Methods 14:149-167.

Rodgers RJ, Johnson NJT (1995) Factor analysis of spatiotemporal and ethological measures in the murine elevated plus-maze test of anxiety. Pharmacol Biochem Behav 52:297-303.

Rodgers RJ, Shepherd JK (1993) Influence of prior maze experience on behaviour and response to diazepam in the elevated plus-maze and light/dark tests of anxiety in mice. Psychopharmacology 113:237-242.

Rodgers RJ, Lee C, Shepherd JK (1992) Effects of diazepam on behavioural and antinociceptive responses to the elevated plus-maze in male mice depend upon treatment regimen and prior maze experience. Psychopharmacology 106:102-110.

Rodgers RJ, Johnson NJT, Cole JC, Dewar CV, Kidd GR, Kimpson PH (1996) Plus-maze retest profile in mice: importance of initial stages of trial 1 and response to post-trial cholinergic receptor blockade. Pharmacol Biochem Behav 54:41-50.

Sprouse JS, Aghajanian GK (1987) Electrophysiological response of serotonergic dorsal raphe neurones to $5-\mathrm{HT}_{1 \mathrm{~A}}$ and $5-\mathrm{HT}_{1 \mathrm{~B}}$ agonists. Synapse 1:3-9.

Thiébot M-H, Jobert A, Soubrié P (1980a) Conditioned suppression of behavior: its reversal by intra raphe microinjection of chlordiazepoxide and GABA. Neurosci Lett 16:213-217.

Thiébot M-H, Jobert A, Soubrié P (1980b) Chlordiazepoxide and GABA injected into raphe dorsalis release the conditioned behavioural suppression induced in rats by a conflict procedure without nociceptive component. Neuropharmacology 19:633-641.

Thiébot M-H, Soubrié P, Hamon M, Simon P (1984) Evidence against the involvement of serotonergic neurons in the anti-punishment activity of diazepam in the rat. Psychopharmacology 82:355-359.

Treit D, Menard J, Royan C (1993) Anxiogenic stimuli in the elevated plus-maze. Pharmacol Biochem Behav 44:463-469.

Trulson ME, Preussler DW, Howell GA, Frederickson CJ (1982) Raphe unit activity in freely moving cats: effects of benzodiazepines. Neuropharmacology 21:1045-1050.

Turner DM, Sapp DW, Olsen RW (1991) The benzodiazepine/alcohol antagonist Ro 15-4513: binding to a $\mathrm{GABA}_{\mathrm{A}}$ receptor subtype that is insensitive to diazepam. J Pharmacol Exp Ther 257:1236-1242.

Wang Q-P, Nakai Y (1993) Enkephalinergic innervation of GABAergic neurons in the dorsal raphe nucleus of the rat. Brain Res Bull 32: $315-320$. 